\title{
Alexandre Dumas, Correspondance générale
}

\section{Lise Sabourin}

\section{OpenEdition}

\section{Journals}

Édition électronique

URL : http://journals.openedition.org/studifrancesi/523

DOI : 10.4000/studifrancesi.523

ISSN : 2427-5856

\section{Éditeur}

Rosenberg \& Sellier

\section{Édition imprimée}

Date de publication : 1 avril 2015

Pagination : 169-170

ISSN : 0039-2944

\section{Référence électronique}

Lise Sabourin, «Alexandre Dumas, Correspondance générale », Studi Francesi [En ligne], 175 (LIX | I) |

2015, mis en ligne le 01 avril 2015, consulté le 18 septembre 2020. URL : http://

journals.openedition.org/studifrancesi/523 ; DOI : https://doi.org/10.4000/studifrancesi.523

Ce document a été généré automatiquement le 18 septembre 2020.

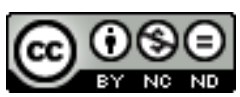

Studi Francesi è distribuita con Licenza Creative Commons Attribuzione - Non commerciale - Non opere derivate 4.0 Internazionale. 


\title{
Alexandre Dumas, Correspondance générale
}

\author{
Lise Sabourin
}

\section{RÉFÉRENCE}

ALEXANDRE DUMAS, Correspondance générale, t. I, édition de Claude schopP, Paris, Classiques Garnier, 2014, pp. 611.

1 Après les diverses correspondances particulières (à Sand, à Mélanie Waldor, à son fils), relatives à une œuvre (concernant Christine, les Mémoires, les Mousquetaires) ou les choix plus ou moins nombreux de lettres (200 pour un bicentenaire en 2002), publiées durant ces quarante dernières années, voici que Claude Schopp s'engage dans ce qu'il nomme en son introduction (pp. 7-12) un «essai» de Correspondance générale d'Alexandre Dumas père. Travail en effet peu aisément exhaustif puisque, outre son énormité, sa dispersion, sa destruction partielle, les conditions même de vie de l'auteur le rendent forcément difficile à réunir. Cependant, se fondant dans la mesure du possible sur les autographes, notamment des fonds importants de la Bibliothèque nationale de France, de l'Arsenal, de la Bibliothèque de l'Institut, des Archives nationales, de quelques bibliothèques étrangères et du fonds Glinel acquis par la Société des amis d'Alexandre Dumas, il présente dans ce premier volume les lettres de 1820 à 1832, avec chronologie annuelle, répertoire des correspondants, index des noms de personnes et des œuvres citées, ainsi qu'en annexes les documents liés au procès contre Harel, à la création de Christine et à la reconnaissance de ses deux enfants naturels, Marie et Alexandre fils.

2 Ce premier tome correspond à l'émergence du talent dramatique de Dumas que ses lettres permettent de suivre dans son ascension de plus en plus éclatante. D'abord les aléas de Christine, acceptée «avec corrections» à la Comédie-Française puis remplacée par Henri III sur fond de concurrence avec la Christine de Suède de Brault: Dumas la cède alors à Harel pour l'Odéon avant d'engager un procès en rétrocession, perdu pour son «succès... peut-être» comme conclut le jugement (p. 466). Puis Dumas chemine d'Édith à 
Antony, le drame qui contient «bien des choses de [la] vie» vécue avec Mélanie Waldor (p. 216), correspondante très abondante de ce volume, au fil des quatre années partagées depuis les premières lettres énamourées jusqu'au testament qu'elle écrit (pp. 284-285) dans la conviction de ses infidélités et aux lettres d'après rupture et pardon (pp. 330-332 et 348). La création de La Tour de Nesle enfin, en 1832, entame les problèmes de collaboration, en l'occurrence avec Gaillardet, qui hanteront toute la carrière de Dumas.

3 On relira aussi avec plaisir dans ce volume les lettres échangées avec Hugo et Vigny. Par exemple, au soir de la réception du More de Venise le 4 août 1829, une mention qui ne manque pas de piquant pour un dramaturge lui-même joué sur les planches du Théâtre-Français: «il semble que ces automates royaux soient devenus poètes pour vous comprendre» (p. 161). Le déplacement en Vendée après la «part assez active» (p. 242) prise par Dumas aux événements de 1830 ou l'échappée avec Belle Kreissalmner de Suisse à Turin offrent également des descriptions intéressantes sous la plume épistolaire de celui qui deviendra un écrivain voyageur. 